\title{
Combustion of Straight Glycerol With/Without Methane Using a Fuel-Flexible, Low-Emissions Burner
}

\author{
Lulin Jiang and Ajay K Agrawal *
}

\begin{abstract}
In this study, we present a fuel-flexible dual-fuel combustor to simultaneously burn methane and/or straight glycerol without preheating either glycerol or air by utilizing a novel flow-blurring (FB) liquid fuel injector. Product gas temperature, $\mathrm{NO}_{\mathrm{X}}$ and $\mathrm{CO}$ emissions at multiple locations inside the combustor are measured to quantitatively assess the flame structure, related to liquid atomization, droplet evaporation, and fuel-air mixing in the near field. For fixed total heat release rate, the impact of fuel mix on combustion performance is investigated by varying the methane gas and glycerol flow rates. For the same fuel mix, air to liquid mass ratio effect is evaluated by varying the atomizing air flow rate. Pure glycerol flame is also investigated to demonstrate the fuel flexibility and ease of switching between gas and liquid fuels in the present system. Results show that the methane combustion can assist glycerol vaporization to results in its rapid oxidation. In spite of the differences in the flame structure, profiles of product gas temperature and emissions at the combustor exit reveal that complete and mainly lean premixed combustion with low emissions is achieved for all of the test cases indicating excellent fuel flexibility of the present combustor using the FB injector.
\end{abstract}

\section{Keywords:}

Straight Glycerol; Dual Fuel Combustor; Liquid Fuel Atomization; Low Emission Combustion; FuelFlexibility

\section{Introduction}

Increasing worldwide demand for energy and depleting fossil fuel resources have drawn attention to research on alternative fuels. Biodiesel is an attractive renewable drop-in fuel because it can replace diesel in existing combustion systems with minimal hardware modifications [1-3]. However, about $1 \mathrm{~kg}$ of crude glycerol is generated for $9 \mathrm{~kg}$ of biodiesel produced [4-6]. Even though pure glycerol finds applications in food, cosmetics and pharmaceutical industries, it is too costly for biodiesel producers to refine crude glycerol into high purity glycerol. Therefore, glycerol generated during biodiesel production is often considered a waste product. Disposal of glycerol is an emerging environmental issue in producing and utilizing biodiesel. Glycerol could be blended with gasoline to recover some of its chemical energy in the form of an alternative fuel [7]. Glycerol can also be an attractive feedstock for producing chemicals such as 1,3-propanediol with end uses for corterra polymers, solvents and anti-freeze, etc [8,9]. Using Enterobacter Aerogenes HU-101 to convert glycerol into fuels such as hydrogen and ethanol has been studied for future portfolio of alternative fuels [10]. While the previous research offers routes to convert glycerol into useful products, significant cost and energy is still required. For example, anaerobic digestion of glycerol recovers only about three-forth of the total available energy [11]. 
Previous research has shown that glycerol is combustible, in spite of its low heating value and high ignition temperature. Direct combustion of glycerol can be an economically viable solution to effectively utilize it to meet some of our energy needs. Recently, McNeil et al. [12] achieved glycerol combustion in a compression ignition engine by supplying air at above $90^{\circ} \mathrm{C}$ and glycerol at around $144^{\circ} \mathrm{C}$ to decrease the kinematic viscosity and to overcome the high ignition temperature characteristic of glycerol. Results showed low emissions of carbon monoxide (CO), nitric oxides $\left(\mathrm{NO}_{\mathrm{X}}\right)$, and particulates, and low emissions of carbonyl such as acrolein from glycerol operation when compared to equivalent engines operating on diesel or biodiesel fuel. For continuous flow applications such as gas turbines and industrial burners, Bohon et al. [13] used an air-assist atomizer (Delavan model 30609-3) to create the glycerol spray. Glycerol was cleanly and stably burned in a 7 $\mathrm{kW}$ swirl-stabilized burner with a steel restrictor at the combustor exit to improve internal flow recirculation in the combustion chamber. High swirl numbers of 2 to 10 were utilized to create recirculation in the spray zone and to improve atomization. In this study, a larger scale furnace with the capacity of $82 \mathrm{~kW}$ was also used, whereby crude glycerol was preheated to $93^{\circ} \mathrm{C}$ and atomizing air was preheated to $150^{\circ} \mathrm{C}$ before the two fluids were supplied to the fuel injector. Preheating glycerol decreases its kinematic viscosity to levels similar to conventional fuel oils, which is important to create a fine spray. Queirós et al. [14] used two air-assist injectors to atomize crude glycerol preheated to $80^{\circ} \mathrm{C}$ and co-combusted it with natural gas and hydrogen. Higher $\mathrm{CO}$ and unburned hydrocarbon (UHC) emissions were detected than those from pure gaseous fuel combustion. Steinmetz et al. [15] preheated both air and crude glycerol atomized by Delavan airassist fuel injectors. Crude glycerol flames yielded negligible amounts of acrolein, but produced large quantities of submicron particulate emissions and residues from the soluble catalysts contained in the crude glycerol, suggesting multiple challenges in utilizing the crude glycerol fuel.

In prior studies, typically the glycerol was preheated to reduce the kinematic viscosity so that it could be atomized by existing air-blast $(\mathrm{AB})$ or air-assist fuel injectors that work on the principle of destabilizing the shear layer of the fuel jet to create the spray [16, 17]. However, the high kinematic viscosity of the fuel suppresses the shear layer instabilities, which limits the ability of the existing injectors to produce a fine spray for high viscosity fuels supplied at the room temperature [18]. For example, emissions from combustion of straight vegetable oil (VO) atomized by an AB injector at room temperature were beyond the measurement range of the gas analyzer [18]. Cleaner combustion of straight VO using an AB injector was obtained by preheating the fuel [19]. Recently, our research group has developed a fuel-flexible combustion system that not only allows sustainable application of alternative fuels with wide range of physical and chemical properties, but also makes it easier to switch from conventional fuels such as methane, kerosene, diesel, etc, to alternative fuels such as biodiesel, VO, and glycerol [20-24]. The combustion system relies upon the flow-blurring (FB) injector reported first by Gañán-Calvo [25] to create "five to fifty times" more fuel surface area than a plain-jet $\mathrm{AB}$ atomizer.

The fuel injector illustrated in Fig. 1(a) consists of a fuel tube and an exit orifice both of diameter, $\mathrm{D}$ and a gap $\mathrm{H}$ between the fuel tube tip and the orifice [25]. For $H / D<0.25$, the atomizing air bifurcates as it reaches the gap between the orifice and the fuel tube tip. A portion of the atomizing air flows into the fuel tube, while the rest leaves the injector through the orifice. The turbulent twophase flow created inside the fuel tube, also leaves the injector through the orifice [25]. Significant decrease of pressure in the orifice causes air bubbles in the two-phase mixture to expand and break apart the surrounding liquid into fine droplets. Internal flow visualization has shown the formation of air bubbles at the tip of the inside liquid supply tube of the FB injector [26]. 
Previous studies have shown that the FB injector, compared to an $\mathrm{AB}$ injector, creates water spray with finer droplets with lower energy input, i.e. lower pressure drop in the atomizing airline [27-29]. Droplet size distributions measured by Phase Doppler Particle Analyzer (PDPA) in non-reacting diesel and straight vegetable oil (VO) sprays as well as in reacting sprays of highly viscous straight glycerol show that the FB injector produces fine sprays with flow-weighted average Sauter Mean Diameter (SMD) of 30 to $40 \mu \mathrm{m}$ at axial locations of 2.0 to $10.0 \mathrm{~cm}$ downstream of the injector exit [21, 22, 28, 29]. Clean and stable combustion of kerosene, diesel and biodiesel has been achieved using the FB injector in a $7 \mathrm{~kW}$ swirl stabilized burner [20-24, 30]. FB injector has been shown to produce stable and clean blue flames of high viscosity fuels yielding very low $\mathrm{CO}$ and $\mathrm{NO}_{\mathrm{X}}$ emissions at the combustor exit [20-24,30]. Table 1 compares the key physical properties of diesel, biodiesel, and glycerol fuels used in these studies. Recently, Niguse et al. scaled up the small scale burner with the FB injector to industrial capacity of heat release rate (HRR) of up to $60 \mathrm{~kW}$ [31]. Diesel and straight VO were stably combusted with low emissions in this scaled up system signifying the versatility of FB atomization for industrial applications. High-speed imaging technique and time-resolved Particle Image Velocimetry (PIV) have revealed that the FB injector produces fine and stable sprays of water as well as glycerol in the near field of the injector exit [3234]. The PIV image in Fig. 2(b) illustrates that the glycerol is broken into fine streaks and droplets, with thickness or diameter of less than $40 \mu \mathrm{m}$, immediately at the injector exit because of the primary FB atomization within the injector [33]. The streaks are quickly disintegrated into finer droplets by Rayleigh-Taylor instabilities resulting from interactions with the high-velocity atomizing air at the injector exit [33].

Prior studies have demonstrated combustor operation with glycerol including emissions reported at the exit plane only $[23,31]$. In this research, combustion of straight (unheated) glycerol with and without methane gas is investigated to assess the fuel flexibility and ease of switching fuels in a combustor utilizing the FB injector. The product gas temperature and emissions data at various axial and radial locations inside the combustor are acquired for a fix total air flow rate to quantify the flame structure and thus, to infer liquid fuel atomization, droplet vaporization, and fuel-air mixing processes. For a fixed total heat release rate (HRR), different amounts of methane and glycerol fuels are introduced to compare the burner performance. For fixed fuel mix, the effect of the air-to-liquid mass ratio (ALR) is investigated by varying the atomizing air flow rate. The following sections describe the experimental approach, results, and conclusions.

\section{Experimental Setup}

Fig. 2 shows the schematic of the experimental setup. After passing through filters and water traps, the compressed air is separated into primary airflow and atomizing airflow lines. Primary airflow enters the mixing chamber through the plenum filled with marbles to breakdown the large vortical structures. Methane is introduced into the mixing chamber, and the fuel-air mixture or primary airflow pass through a section filled with steel wool to further homogenize the flow. This flow is introduced into the open-ended insulated quartz combustor through a swirler with axial curved vanes at 30 degree angle with respect to the transverse plane providing swirl number of approximately 1.5 . The cylindrical combustor is insulated with $5.0 \mathrm{~cm}$ thick fiber glass layer. The fuel injector consists of a central fuel port with sidewise fuel inlet attachment and multiple openings around the peripheral region to introduce the atomizing air. Liquid fuel enters the injector via tubing connected with the injector holder and atomizing air is supplied from the bottom of the injector holder. FB injection concept is implemented by placing a spacer of width $H=0.25 D$ between the 
fuel tube tip and injector orifice. In this study, $D=1.5 \mathrm{~mm}$ and $H=0.375 \mathrm{~mm}$. Mass flow rates of air and methane are controlled and measured by Sierra Smart Track 2 Series 100 mass flow controllers with accuracy of $\pm 1 \%$ of the reading. Liquid fuel is supplied by a Cole Parmer high performance peristaltic metering pump (Model 7523-90) with an accuracy of $\pm 0.25 \%$ of the reading.

R-type thermocouple insulated by ceramic tubes to minimize axial heat conduction is used to measure the product gas temperature. The thermocouple wire diameter was $0.25 \mathrm{~mm}$ and the bare bead diameter was $1.5 \mathrm{~mm}$. The external surface temperature of the insulated combustor is measured by an infrared camera (FLIP-T620) to estimate the heat loss through the combustor wall. An in-house built, helium-cooled emission probe made of two coaxial quartz tubes that enable mixing of combustion products and helium within the outer tube is used to sample the product gas from inside the combustor. Helium with its high specific heat capacity reduces the temperature of the sampled combustion products to quench reactions near the probe tip. The helium concentration in the sampled product is approximately $20 \%$ (by volume), and it is measured by a real-time Airsense High Speed Multi-component Gas Analyzer with an accuracy of $\pm 2 \%$. For combustion of $100 \%$ straight glycerol, the Airsense gas analyzer is also utilized to detect the emissions of acrolein and acetaldehyde. The $\mathrm{CO}$ and $\mathrm{NO}_{\mathrm{x}}$ emissions are measured using Nova model 376WP gas analyzer with accuracy of $\pm 2 \mathrm{ppm}$. The sampled gas is passed through an ice bath and filters to condense and remove the water, before it is analyzed by the gas analyzers. The sampled data are corrected for helium dilution and are reported as such.

The experiment is started with pure methane combustion to preheat the system and then, glycerol (USP grade with $99+\%$ purity) is gradually introduced into the combustion system through the FB injector. The total airflow rate, which is the sum of the primary airflow rate through the swirler and atomizing air through the injector, is kept constant at 150 standard liters per minute (slpm) for all test cases. For co-combustion of methane and glycerol, the total HRR of $7.9 \mathrm{~kW}$ is kept constant. First, for a fixed ALR of 2.23, the flame structure is investigated for two fuel mixes, G45 and G68, where G45 signifies that $45 \%$ of the HRR is from glycerol and the rest is from methane. For the fuel mix with $68 \%$ of the HRR from glycerol (i.e., G68), the effect of ALR is investigated for the case G68A with ALR $=1.47$. The detailed structure of the pure glycerol flame, i.e., G100 is also obtained for $\mathrm{HRR}=7 \mathrm{~kW}$ and ALR $=1.13$ which pertains to the optimum operating conditions in the burner. Table 2 lists the fuel and airflow rates for these four test cases. G45, G68/G68A and G100 represent equivalence ratio of $0.92,0.90$ and 0.77 , respectively. The equivalence ratio for the G100 fuel mix is smaller than the remaining cases because of the smaller heating value of the glycerol fuel. The Chemkin-pro software was used to compute the adiabatic flame temperature $\left(\mathrm{T}_{\mathrm{ad}}\right)$ at equilibrium for the experimental conditions listed above. Results in Fig. 3 show that the computed $\mathrm{T}_{\mathrm{ad}}$ is $2156 \mathrm{~K}$, $2134 \mathrm{~K}$ and $1972 \mathrm{~K}$, respectively, for G45, G68/G68A and G100 cases. Note that $T_{\text {ad }}$ represents temperature achieved for complete combustion without heat loss from the combustor wall. However, the combustor used in the present study results in unavoidable heat loss, which can be significant even with the insulation layer. The estimated cumulative heat loss through the insulated combustor wall is around $507 \mathrm{~W}, 486 \mathrm{~W}$ and $488 \mathrm{~W}$, respectively for G45, G68 and G68A, and the respective average outside combustor wall temperature is $442 \mathrm{~K}, 426 \mathrm{~K}$, and $427 \mathrm{~K}$. The local flame temperature is related to the local equivalence ratio determined by fuel atomization, fuel prevaporization, and fuel-air mixing processes, which vary greatly throughout the combustor. 


\section{Results and discussions}

\subsection{Co-Combustion of Methane and Glycerol}

Fig. 4 shows temperature (uncorrected) contours for flames with different fuel mixes, inferred from thermocouple measurements at 10 axial and 11 transverse planes within the combustor. Significant differences in the thermal structure are observed for the three test cases. For G45 flame, the reaction zone is close to the combustor dump plane (or injector exit) where uncorrected temperature of up to $1800 \mathrm{~K}$ is measured. Since methane enters the combustor premixed with the combustion air, it reacts closer to the dump plane. Evidently, methane lean premixed (LPM) combustion provides thermal feedback in the center region of the burner to quickly vaporize glycerol droplets. The evaporated fuel subsequently mixes with relatively hot products of methane combustion to result in rapid oxidation, yielding in relatively narrow and short reaction zone between $\mathrm{z}=0.0$ and $10.0 \mathrm{~cm}$. In G68 flame, a low temperature region (or dark zone) representing fuel pre-vaporization and fuelgas premixing in the center region $(\mathrm{y}<+/-1 \mathrm{~cm})$ near the injector exit $(\mathrm{z}<6 \mathrm{~cm})$ is observed. Higher gas temperatures in the annular region around the dark zone are indicative of LPM combustion of methane. The high temperature region downstream of the dark zone, i.e. between $\mathrm{z}=$ $7.0 \mathrm{~cm}$ and $20.0 \mathrm{~cm}$ represents the reaction zone for glycerol, mostly prevaporized upstream. The lifted and elongated reaction zone of the G68 flame can be attributed to two factors that increase the distance required to fully prevaporize the fuel: (a) higher glycerol and atomizing air flow rates through the injector increase the droplet velocity in the spray, and (b) reduced thermal feedback from methane combustion increases the droplet lifetime or the time to fully vaporize the fuel droplet. Downstream of the primary reaction zone, the product gas temperature for both cases (G45 and G68) decreases as the oxidation reactions approach completion, and hence, the heat loss rate to the ambient exceeds the heat release rate by chemical reactions. Even though the primary reaction zone locations are different for the two cases, the product gas temperature profiles in the downstream region of the burner match each other indicating excellent fuel-flexibility of the present combustor utilizing the FB injector.

Next, the impact of ALR on methane/glycerol flame structure is investigated by comparing G68 and G68A cases. In G68A case, approximately $1 / 3^{\text {rd }}$ less atomizing airflow is supplied through the injector to reduce the ALR to 1.47. Fig. 4(c) shows the contours of temperature (uncorrected) inside the combustor for the G68A flame. Compared to G68 case in Fig 4(b), G68A flame depicts a dark pre-vaporization and premixing zone with lower temperatures. For G68A case, the low temperature region extends across the width of the combustor indicating reduced thermal feedback from the now very lean LPM combustion of methane at the dump plane. A compact primary reaction zone is observed between $\mathrm{z}=5.0 \mathrm{~cm}$ and $12.0 \mathrm{~cm}$, with peak temperatures occurring towards the periphery of the burner. Lower ALR for G68A case results in larger but slower moving fuel droplets in the spray. Both of these effects tend to increase the thermal energy required to pre-vaporize the fuel droplets which decreases the gas temperature near the injector exit. Increased thermal feedback to the spray also prevents the stabilization of LPM methane flame at the dump plane. Thus, both methane and pre-vaporized glycerol react mainly in the premixed mode in the downstream reaction zone. Some larger droplets, usually located at the spray periphery, might also burn in partially premixed or diffusion mode. In our previous studies, clean blue flames were visualized through a transparent quartz combustor for diesel, biodiesel, straight VO, and glycerol with/without methane as the result of excellent FB atomization and the subsequent LPM combustion [23, 24]. In the present study, with less heat losses through the insulated combustor wall, clean blue flames are also expected for all test cases. Overall, G45 flame is the shortest as demonstrated by the thermal 
structure in Fig. 4(a). G68 flame is lifted and elongated because of greater glycerol component requiring longer residence time for pre-vaporization and fuel-air mixing. Compared to G68 flame, G68A flame is expected to be wider because of the lower ALR increasing the number of larger droplets migrating towards the spray periphery [32-34].

Next, axial profiles of product gas temperature and $\mathrm{NO}_{\mathrm{X}}$ and $\mathrm{CO}$ emissions at various transverse locations for the three test cases are shown in Fig. 5. Transverse locations represented include combustor centerline $(\mathrm{y}=0.0 \mathrm{~cm})$, combustor periphery $(\mathrm{y}=3.24 \mathrm{~cm})$ and an in-between location at $\mathrm{y}=2.30 \mathrm{~cm}$. Fig. 5a-1 quantitatively compares the gas temperature profiles for the three test cases along the combustor centerline. For G45, high gas temperatures of $1800 \mathrm{~K}$ to $2000 \mathrm{~K}$ near the dump plane, between $\mathrm{z}=0.0$ and $8.0 \mathrm{~cm}$, signify rapid methane LPM combustion assisting glycerol vaporization and combustion as discussed previously. For $\mathrm{z}>10 \mathrm{~cm}$, a small increase in gas temperature signifies minor secondary reactions before a gradual decline in temperature of about 200 $\mathrm{K}$ by the heat loss to the ambient. For G68 case, the temperature is lower near the dump plane, and it peaks to about $1800 \mathrm{~K}$ at $\mathrm{z}=12.0 \mathrm{~cm}$ or the mid-point of the downstream reaction zone. For G68A case, gas temperatures in the pre-vaporization and reaction zones are lower than those for the G68 case. In spite of these near-field differences, the gas temperature profiles in the latter one-third length of the combustor are nearly the same for the three test cases.

Fig. 5a-2 presents the axial profiles of $\mathrm{NO}_{\mathrm{X}}$ concentration along the combustor centerline for the three test cases. For $\mathrm{G} 45$ case, $\mathrm{NO}_{\mathrm{X}}$ concentration is about $25 \mathrm{ppm}$ at $\mathrm{z}=10.0 \mathrm{~cm}$ and it remains nearly constant in the remaining length of the combustor. Evidently, $\mathrm{NO}_{\mathrm{X}}$ has already formed in the high temperature reaction zone near the dump plane. For G68 case, higher $\mathrm{NO}_{\mathrm{X}}$ concentration of about $33 \mathrm{ppm}$ at $\mathrm{z}=10.0 \mathrm{~cm}$ is observed than G45 case. For G68 case, the $\mathrm{NO}_{\mathrm{X}}$ emissions also increase in the elongated reaction zone at $\mathrm{z}>10.0 \mathrm{~cm}$. The $\mathrm{NO}_{\mathrm{X}}$ emission at $\mathrm{z}=10.0 \mathrm{~cm}$ matches that for G68 case, but without the elongated reaction zone, it remains nearly constant in the axial direction for the former case. For all cases, most of the $\mathrm{NO}_{\mathrm{X}}$ is formed within $\mathrm{z}=10.0 \mathrm{~cm}$. Assuming thermal mechanism as the dominant pathway, the $\mathrm{NO}_{\mathrm{X}}$ emissions would depend upon the residence time in the high temperature region. Figs. 4 and 5a-1 show that high temperature region is the shortest for G45 case and the longest for G68 case. Consequently, the $\mathrm{NO}_{\mathrm{X}}$ emissions are the lowest for G45 case and the highest for G68 case and in between for G68A case. ALR affects the methane-air equivalence ratio as well as glycerol vaporization and premixing with air, which can also influence the $\mathrm{NO}_{\mathrm{X}}$ production. Further, the liquid and gas velocity ratio could affect the atomization, but this parameter has not been explored in the present study. However, the $\mathrm{NO}_{\mathrm{X}}$ emissions are very low for all cases, indicting clean combustion in the present fuel-flexible burner utilizing the FB injector.

Fig. 5a-3 shows the axial profiles of $\mathrm{CO}$ emissions along the combustor centerline for the three test cases. The gas products are sampled starting from $\mathrm{z}=10 \mathrm{~cm}$ which represents the region after the fuel decomposition and oxidation in the main reaction zone. For all cases, $\mathrm{CO}$ emissions are very low $(<40 \mathrm{ppm})$, especially in view of the adverse physical properties of glycerol compared to diesel or biodiesel (see Table 2); extremely high kinematic viscosity, very low heating value, high heat of vaporization, and high ignition temperature. For all cases, an increase in $\mathrm{CO}$ emissions towards the combustor exit is likely caused by the few larger droplets reaching farther downstream without fully vaporizing or combusting. For G68A, CO emissions decrease in the secondary reaction zone between $\mathrm{z}=10.0 \mathrm{~cm}$ and $20.0 \mathrm{~cm}$, which is likely located upstream $(\mathrm{z}<10 \mathrm{~cm})$ for G45 and G68 cases. Axial profiles of temperature, and $\mathrm{NO}_{\mathrm{X}}$ and $\mathrm{CO}$ emissions in Figs. 5b for $\mathrm{y}=$ $2.30 \mathrm{~cm}$ and in Figs. $5 \mathrm{c}$ for $\mathrm{y}=3.24 \mathrm{~cm}$ show similar trends. 
Fig. 6 presents the transverse profiles of product gas temperature (uncorrected) and $\mathrm{NO}_{\mathrm{X}}$ and $\mathrm{CO}$ emissions at the combustor exit plane for the three test cases with the same HRR of $7.9 \mathrm{~kW}$. Two experimental data sets are shown in Fig. 6 to depict the repeatability of gas temperature and emissions measurements. Results show that the measurement uncertainties for temperature, $\mathrm{NO}_{\mathrm{X}}$, and $\mathrm{CO}$ emissions are within $10 \mathrm{~K}, 3 \mathrm{ppm}$, and $5 \mathrm{ppm}$, respectively. Even though the near field processes of fuel atomization, fuel vaporization, fuel-air mixing, and chemical reactions are different, overlapping profiles of gas temperature at the combustor exit plane in Fig. 6(a) indicate complete combustion and only minor effects of the fuel mix. For each case, $\mathrm{NO}_{\mathrm{X}}$ emissions (Fig 6b) are nearly uniform across the combustor width except for a minor dip near the wall for G68 and G68A cases. For all cases, $\mathrm{CO}$ emissions in the mid-section of the combustor $(\mathrm{y}<+/-2.5 \mathrm{~cm})$ are within $50 \mathrm{ppm}$, which is extremely low for combustion of straight glycerol. CO emissions are higher around the combustor periphery because of the slower chemical reaction rates resulting from the locally reduced product gas temperatures. Across the combustor width, $\mathrm{CO}$ emissions are the lowest for G45 case and the highest for G68A case and in between for G68 case. Evidently, CO emissions increase with increasing liquid fuel flow rate, and then, for a given liquid fuel flow rate, by decreasing the atomizing airflow rate. Each of these conditions increases the production of larger droplets that take longer to fully vaporize and hence, glycerol from some of these larger droplets might not react completely within the residence time of the combustor, especially near the low temperature wall region for G68A case.

Even though there are slight variations with fuel mixes, both $\mathrm{NO}_{\mathrm{X}}$ and $\mathrm{CO}$ emissions in the present study are quite low, especially compared to results of co-combustion of glycerol/methane/hydrogen by Queirós et al. [14]. Even with glycerol preheated to $80^{\circ} \mathrm{C}$ to decrease its kinematic viscosity by more than 10 times compared to that at room temperature, $\mathrm{CO}$ emissions of three-digit ppm level were detected by Queirós et al. [14] and CO concentrations increased with the increasing glycerol percentage above $45 \%$ of the total HRR. Queirós et al. [14] found $\mathrm{NO}_{\mathrm{X}}$ emissions of around $10-20 \mathrm{ppm}$ for operation at equivalence ratio of 0.76 which is much lower than the equivalence ratio (and hence, product gas temperature) of 0.90-0.92 in the present study. For a given fuel mix, $\mathrm{NO}_{\mathrm{X}}$ emissions increased with an increase in ALR [14] which agrees with the present results. In present study, particulate matter (PM) was visually absent in the combustion products. PM is mainly generated from the pyrolysis process around large droplets burning in the diffusion mode and/or inherent ash and residual catalysts in the glycerol fuel. The absence of PM in this study is attributed to two reasons: (a) fine glycerol spray resulting in the clean LPM combustion, and (b) ash content not included in the USP grade glycerol. Overall, the present study shows that when co-fired with methane, most of the glycerol supplied at room temperature is burned in clean LPM combustion mode, demonstrating great atomization capability of the FB injector.

\section{2. Straight Glycerol Combustion}

After successfully co-firing methane/glycerol, the fuel flexible burner is also investigated by combusting straight glycerol, represented as G100 case. Similar to previous cases, combustion performance of G100 case is documented by product gas temperature and $\mathrm{NO}_{\mathrm{X}}$ and $\mathrm{CO}$ emissions measured at multiple axial and transverse locations within the combustor. Fig. 7(a) shows lower temperatures at the injector exit where pre-vaporization of glycerol droplets and subsequently, fuelair mixing takes place. The temperature peaks in the mid-region of the reaction zone at around $\mathrm{z}=$ $12.0 \mathrm{~cm}$. The decrease in temperature by heat loss to the ambient is observed only towards the end of the combustion $(z>35 \mathrm{~cm})$ indicating a long secondary reaction zone, which is consistent with the distributed glycerol flame zone in an un-insulated quartz combustor observed by Simmons et al 
[23]. Except near the dump plane, the temperature is higher at the center and lower at the periphery of the combustor, indicating a narrow reaction zone. Note that the equivalence ratio and HRR and hence, the product gas temperature for G100 case is much lower than that for the previous cases.

Fig. 7(b) shows that $\mathrm{NO}_{\mathrm{X}}$ emissions for G100 case are within $10 \mathrm{ppm}$ at all locations which is much lower than methane/glycerol cases but is consistent with the measured gas temperature distributions. Higher fuel bound oxygen in G100 also contributes to lower $\mathrm{NO}_{\mathrm{X}}$ emissions than those from the co-firing of methane and glycerol, which agrees with the findings of Bohon and Roberts [35]. Fig. 7(c) demonstrates that initially higher $\mathrm{CO}$ emissions resulting from fuel decomposition decrease in the flow direction as oxidation reactions take place at $\mathrm{y}=0.0 \mathrm{~cm}$ and 2.3 $\mathrm{cm}$. After reaching the minimum at around $\mathrm{z}=27.0 \mathrm{~cm}, \mathrm{CO}$ emissions increase slightly in the flow direction, indicating incomplete combustion of fuel from some of the larger droplets escaping from the primary and secondary reaction zones. Similarly, $\mathrm{CO}$ emissions near the wall also increase in the flow direction, suggesting that larger droplets reaching the combustor periphery might not undergo complete vaporization and combustion.

At the center of the combustor exit plane, acetaldehyde emission of $0.45 \mathrm{ppm}$ was detected. Because of the high temperature within the combustor, much higher than $280^{\circ} \mathrm{C}$ at which acrolein is generated from thermal decomposition of glycerol [36], acrolein emissions were below the estimated detection limit of $10 \mathrm{ppb}$ for the present instrument. Overall, emissions results for straight glycerol combustion in the present study compare well with those obtained from glycerol combustion in a 7 $\mathrm{kW}$ lab burner by Bohon et al. [13]. Bohon et al [13] detected $\mathrm{NO}_{\mathrm{X}}$ emissions of 7-10 ppm, acrolein within $17.5 \mathrm{ppb}$, and acetaldehyde of $2.25 \mathrm{ppm}$. CO emissions were below the detection limit of 100 ppm [13]. In contrast to Ref 13 utilizing swirling effect to improve AB shear-layer atomization, the temperature profiles and ultra-low $\mathrm{NO}_{\mathrm{X}}$ and $\mathrm{CO}$ emissions within the current combustor quantitatively demonstrate nearly complete, clean, and mainly premixed combustion of straight glycerol by using the FB atomizer.

\section{Conclusions}

Low emission combustion of straight glycerol (unheated) with and without methane has been achieved in a dual-fuel combustor using FB injector. The FB injector generates fine spray near the dump plane, enabling clean combustion of straight glycerol. Thermal feedback from methane LPM combustion further improves glycerol vaporization, fuel-oxidizer mixing and hence, premixed combustion of glycerol. For the same HRR and ALR, higher methane proportion results in a more intense and shorter reaction zone near the combustor dump plane. Reduction in methane flow rate shifts and extends the main reaction zone towards the downstream. For the same fuel mix reducing ALR results in larger, slower-moving droplets requiring greater thermal feedback which reduces the pre-vaporization zone temperature.

In spite of the noticeable differences in the flame structure, nearly complete combustion is achieved for the three test cases, revealed by matching profiles of gas temperature in the latter onethird length of the combustor and low $\mathrm{NO}_{\mathrm{X}}$ and $\mathrm{CO}$ emissions. $\mathrm{NO}_{\mathrm{X}}$ emissions are lowest for G45 flame with intense but shortest reaction zone and highest for G68 flame. Still, for all cases, $\mathrm{NO}_{\mathrm{X}}$ concentrations are within $35 \mathrm{ppm}$ which is very low for the fuels considered. Low $\mathrm{CO}$ emissions $(<40 \mathrm{ppm})$ are also obtained for all three flames although a slight increase in the flow direction is likely caused by incomplete vaporization and combustion of few larger droplets. Compared to the co-fired flames, straight glycerol flame has longer and distributed reaction zone with lower temperature resulting in ultra-low $\mathrm{NO}_{\mathrm{X}}$ and $\mathrm{CO}$ emissions, undetectable acrolein, and negligible 
acetaldehyde. Overall, the dual-fuel burner system, with the application of the FB injector, provides clean combustion with the flexibility to utilize gaseous and/or highly viscous liquid fuels that are difficult to atomize using conventional techniques. While a small scale burner has been investigated in this study, the fuel injector concept can be scaled-up to larger burners with higher HRRs for industrial applications.

\section{Acknowledgments}

This research was supported by the US Department of Energy Award EE0001733.

\section{References}

[1] Graboski MS, McCormick RL. Combustion of fat and vegetable oil derived fuels in diesel engines. Prog Energy Combust Sci 1998; 24(2): 125-64.

[2] Sharp CA, Howell SA, Jobe J. The effect of biodiesel fuels on transient emissions from modern diesel engines, part 1 regulated emissions and performance. SAE Technical Paper No. 2002-01-1967, 2002.

[3] Redel-Macías MD, Pinzi S, Ruz MF, Cubero-Atienza AJ, Dorado MP. Biodiesel from saturated and monounsaturated fatty acid methyl esters and their influence over noise and air pollution. Fuel 2012; 97: 751-6.

[4] Phan AN, Phan TM. Biodiesel production from waste cooking oils. Fuel 2008; 87: 3490-6.

[5] Szybist JP, Boehman AL, McCormick RL, Taylor JD. Evaluation of formulation strategies to eliminate the biodiesel NOx effect. Fuel Process Technol 2005; 86(10): 1109-26.

[6] Szybist JP, Song J, Alam M, Boehman AL. Biodiesel combustion, emissions and emission control. Fuel Process Technol 2007; 88(7): 679-91.

[7] Demirbas A. Conversion of biomass using glycerin to liquid fuel for blending gasoline as alternative engine fuel. Energ Convers Manage 2000; 41(16):1741-8.

[8] Pachauri N, He B. Value-added Utilization of Crude Glycerol from Biodiesel Production: A Survey of Current Research Activities. In: Proceedings of the ASABE Annual International Meeting; Oregon, Portland; 2006. Paper No. 066223.

[9] Wang K, Hawley MC, DeAthos SJ. Conversion of glycerol to 1,3-propanediol via selective dehydroxylation. Ind Eng Chem Res 2003; 42(13): 2913-23.

[10] Ito T, Nakashimada Y, Senba K, Matsui T, Nishio N. Hydrogen and ethanol production from glycerol-containing wastes discharged after biodiesel manufacturing process. J Biosci Bioeng 2005; 100(3): 260-5.

[11]López J, Santos M, Pérez M, Martín M. Anaerobic digestion of glycerol derived from biodiesel manufacturing. Bioresour Technol 2009; 100: 5609-15.

[12] McNeil J, Day P, Sirovski F. Glycerine from biodiesel: The perfect diesel fuel. Process Saf Environ 2012; 90: 180-8.

[13] Bohon MD, Metzger BA, Linak WP, King CJ, Roberts WL. Glycerol combustion and emissions. P Combust Inst 2011; 33: 2717-24.

[14] Queirós P, Costa M, Carvalho RH. Co-combustion of crude glycerin with natural gas and hydrogen. P Combust Inst 2013; 34(2): 2759-67.

[15] Steinmetz SA, Herrington JS, Winterrowd CK., Roberts WL, Wendt JOL, Linak WP. Crude glycerol combustion: Particulate, acrolein, and other volatile organic emissions. P Combust Inst 2013: 34(2): 2749-57.

[16] Lefebvre AH. Airblast Atomization. Progress in Energy and Combustion Science 1980; 6(3): 233-61.

[17] Lefebvre AH. Twin-Fluid Atomization: Factors Influencing Mean Drop Size. Atomization Sprays1992; 2(2): 101-119. 
[18] Panchasara HV, Simmons BM, Agrawal AK, Spear SK, Daly DT. Combustion performance of biodiesel and diesel-vegetable oil blends in a simulated gas turbine burner. J Eng Gas Turb Power 2009; 131(3): 031503 (11 pp).

[19] Panchasara HV, Agrawal AK. Characteristics of preheated bio-oil sprays produced by an air-blast injector. Proceedings of the ASME Turbo Expo 2010; 1: 619-29.

[20] Panchasara HV, Sequera DE, Schreiber WC, Agrawal AK. Emissions reductions in diesel and kerosene flames using a novel fuel injector. J Propul Power 2009; 25(4): 984-7.

[21] Simmons BM. Atomization and Combustion of Liquid Biofuels [dissertation]. Tuscaloosa (AL): University of Alabama at Tuscaloosa; 2011.

[22] Simmons BM, Agrawal AK. Flow and drop size measurements in glycerol spray flames. In: 50th AIAA Aerospace Sciences Meeting Including the New Horizons Forum and Aerospace Exposition; 2012 Jan 9-12; Nashville, Tennessee, USA; 2012. AIAA 2012-0523.

[23] Simmons BM, Kolhe PS, Taylor RP, Agrawal AK. Glycerol Combustion using Flow-Blurring Atomization. In: the 2010 Technical Meeting of the Central States Section of The Combustion Institute, Champaign, Illinoi, 2010.

[24] Jiang L, Agrawal AK, Taylor RP. Clean Combustion of Different Liquid Fuels using a Novel Injector. Exp Therm Fluid Sci 2014; 57: 275-84.

[25] Gañán-Calvo AM. Enhanced liquid atomization: From flow-focusing to flow-blurring. Appl Phys Lett 2005; 86(21): 2141-2.

[26] Agrawal SR, Jiang L, Agrawal AK, Midkiff CK. Analysis of Two-Phase Flow inside a Transparent Fuel Injector. In: the 8th U. S. National Combustion Meeting of the Combustion Institute; 2013 May 19-22; Salt Lake City, Utah, USA; 2013. Paper No. 070HE-0317.

[27] Simmons BM, Panchasara HV, Agrawal AK. A comparison of air-blast and flow-blurring injectors using phase Doppler particle analyzer technique. Proceedings of the ASME Turbo Expo 2009; 2: 98192.

[28] Simmons BM, Agrawal AK. Spray characteristics of a flow-blurring atomizer. Atomization Sprays 2010; 20(9): 821-35.

[29] Simmons BM, Agrawal AK. Drop size and velocity measurements in bio-oil sprays produced by the flow blurring injector. Proceedings of the ASME Turbo Expo 2011; 1: 701-10.

[30] Simmons BM, Agrawal AK. Flow blurring atomization for low-emission combustion of liquid biofuels. Combust Sci Technol 2012; 184(5): 660-75.

[31] Niguse YG, Agrawal AK, Taylor RP, Cox WF. A Novel Fuel-Flexible Combustor for Industrial Applications. In: AFRC 2013 Industrial Combustion Symposium; 2013 Sep 22-25; Sheraton Kauai, Hawaii, USA; 2013.

[32] Jiang L, Agrawal AK, Taylor RP. High speed visualization and PIV measurements in the near field of spray produced by flow-blurring atomization. Proceedings of ASME Turbo Expo 2014: Turbine Technical Conference and Exposition; 2014 Jun 16-20; Düsseldorf, Germany; 2014. ASME Paper GT2014-27199.

[33] Jiang L, Agrawal AK. Investigation of glycerol atomization in the near-field of a flow-blurring injector using time-resolved PIV and high-speed flow visualization. Submitted to Flow Turbul Combust, 2014.

[34] Jiang L, Agrawal AK. Impact of air to liquid mass ratios on the spray features in the near field of a flow-blurring atomizer. In: the Spring Technical Meeting of the Central States Section of the Combustion Institute; 2014 March 16-18; Tulsa, Oklahoma, USA; 2014.

[35] Bohon MD, Roberts WL. NOx emissions from high swirl turbulent spray flames with highly oxygenated fuels. P Combust Inst 2013; 34: 1705-12.

[36] Acrolein, available at http://en.wikipedia.org/wiki/Acrolein (accessed April, 2014). 


\section{LIST OF TABLES AND FIGURES}

Table 1 Physical and chemical properties of diesel, biodiesel and straight glycerol. 2

Table 2 Fuel and air flow rates for all tested cases. 3

Fig. 1 (a) Working principle of the flow blurring injector and (b) Visual image of glycerol spray at ALR of 2 in the near field of a FB injector [28].

Fig. 2 Schematic of the experimental setup of the combustion system. 5

Fig. 3 Adiabatic flame temperatures as the function of equivalence ratio. 6

Fig. 4 Gas temperature contour inside the combustor for (a) G45, and (b) G68 (c) G68A. 7

Fig. 5 Axial profiles of gas temperature, NOX and CO concentrations inside the combustor at three radial locations: (a) combustor centerline, (b) between the wall 8 and centerline and (c) close to the wall.

Fig. 6 Transverse profiles of (a) gas temperature (uncorrected), (b) NOX emissions and (c) $\mathrm{CO}$ emissions at the combustor exit.

Fig. 7 Axial profiles of (a) gas temperature, (b) NOX and (c) CO emissions inside the combustor for pure glycerol combustion (G100). 
Table 1. Physical and chemical properties of diesel, biodiesel and straight glycerol.

\begin{tabular}{llll}
\hline \hline Property & Diesel & Biodiesel & Glycerol \\
\hline Chemical Formula & $\mathrm{C}_{11.125} \mathrm{H}_{19.992}$ & $\mathrm{C}_{18.71} \mathrm{H}_{34.71} \mathrm{O}_{2}$ & $\mathrm{C}_{3} \mathrm{H}_{8} \mathrm{O}_{3}$ \\
Density $\left[\mathrm{kg} / \mathrm{m}^{3}\right], 25^{\circ} \mathrm{C}$ & 834.0 & 880.0 & 1260 \\
Kinematic Viscosity $\left[\mathrm{mm}^{2} / \mathrm{s}\right], 25^{\circ} \mathrm{C}$ & 3.88 & 5.61 & 741 \\
Low Heating Value $(\mathrm{LHV})[\mathrm{MJ} / \mathrm{kg}]$ & 44.6 & 37.66 & 16.2 \\
Auto-ignition Temperature $\left[{ }^{\circ} \mathrm{C}\right]$ & 260 & 177 & 370 \\
Vaporization Temperature $\left[{ }^{\circ} \mathrm{C}\right]$ & $160-370$ & $100-170$ & 290 \\
Surface Tension at $25{ }^{\circ} \mathrm{C}[\mathrm{mN} / \mathrm{m}]$ & 28.2 & 31.1 & 62.5 \\
Heat of Vaporization $[\mathrm{kJ} / \mathrm{kg}]$ & 250 & 200 & 662 \\
\hline
\end{tabular}


Table 2. Fuel and air flow rates for all tested cases.

\begin{tabular}{lcccl}
\hline & G45 & G68 & G68A & G100 \\
\hline Glycerol (mL/min) & 10.69 & 16.15 & 16.15 & 21.00 \\
Methane (slpm) & 7.12 & 4.14 & 4.14 & 0.00 \\
Atomizing air (slpm) & 25.0 & 37.0 & 25.0 & 25.0 \\
Combustion air (slpm) & 125.0 & 113.0 & 125.0 & 125.0 \\
\hline
\end{tabular}




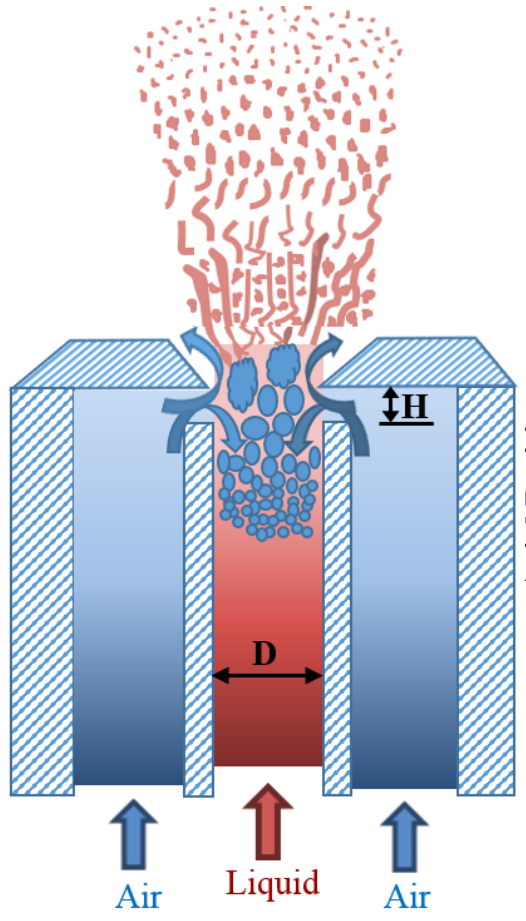

(a)

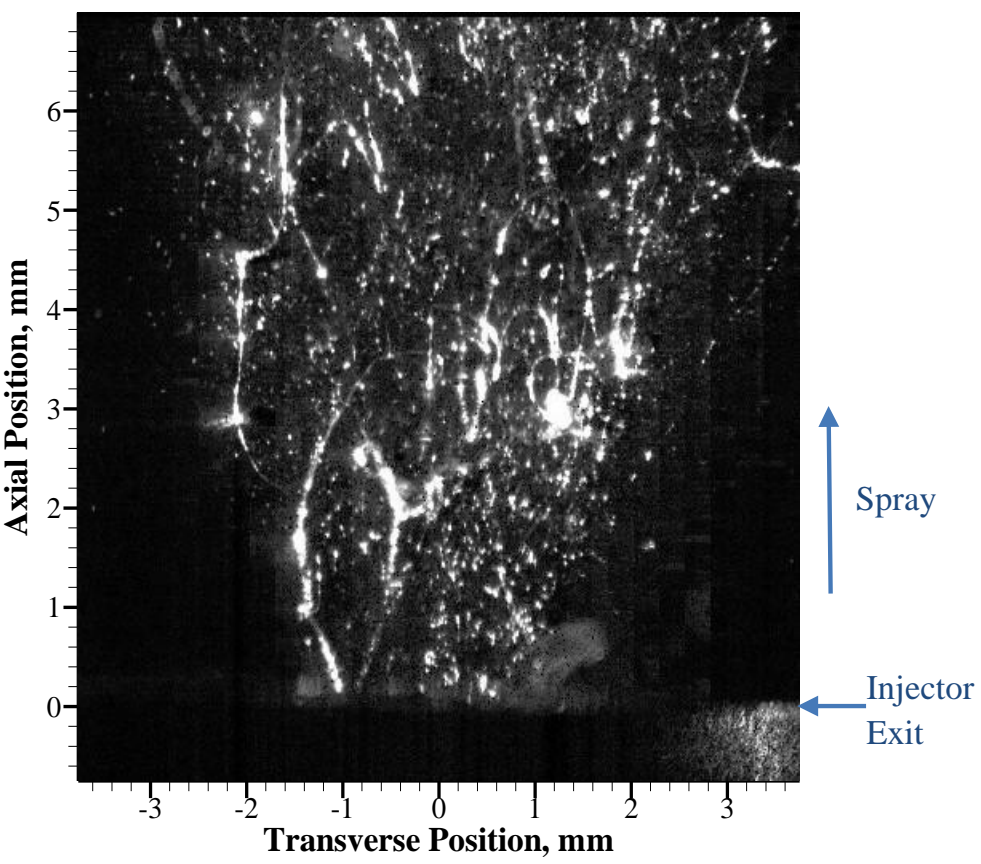

(b)

Fig. 1 (a) Working principle of the flow blurring injector and (b) Visual image of glycerol spray at ALR of 2 in the near field of a FB injector [28]. 


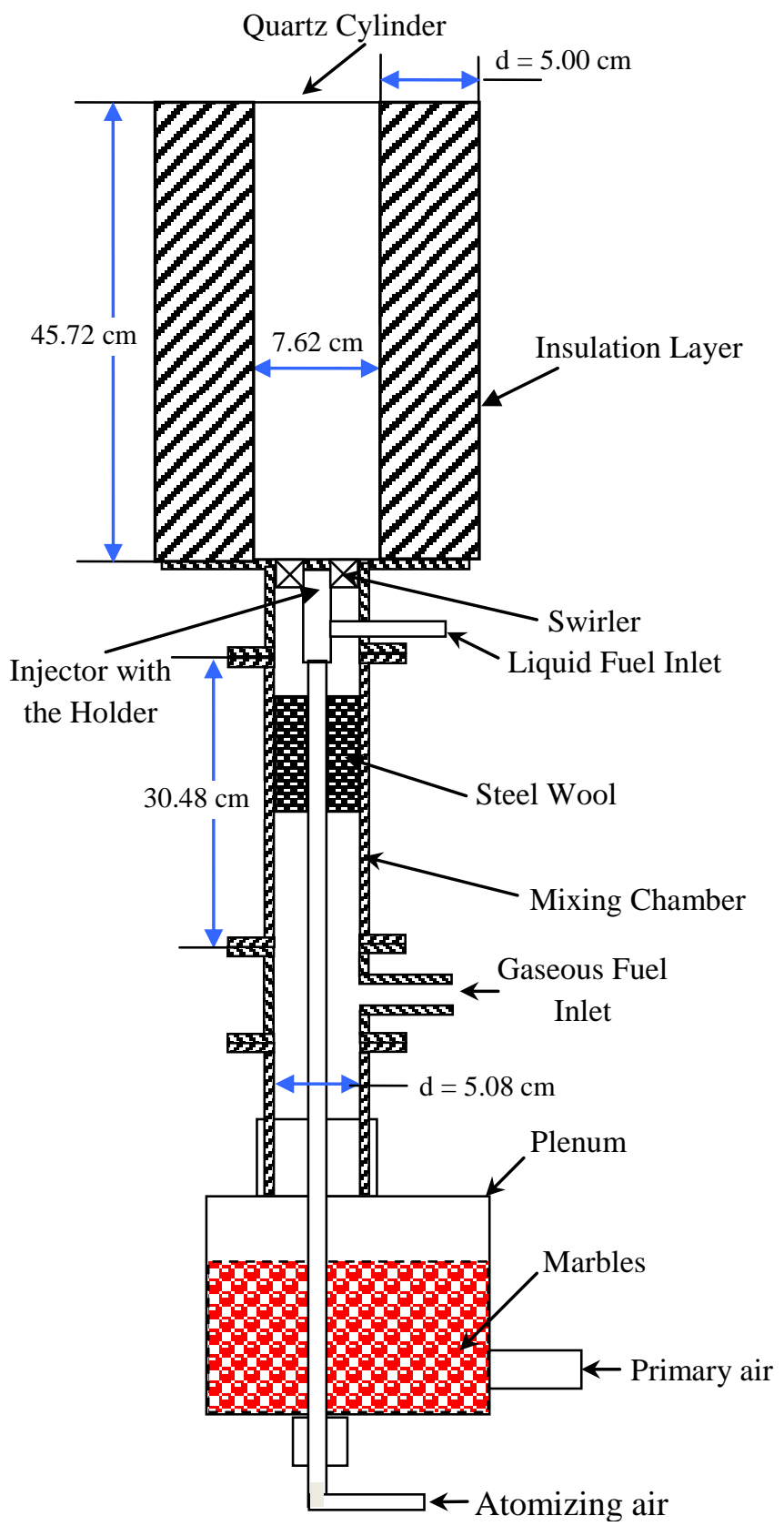

Fig. 2 Schematic of the experimental setup of the combustion system. 


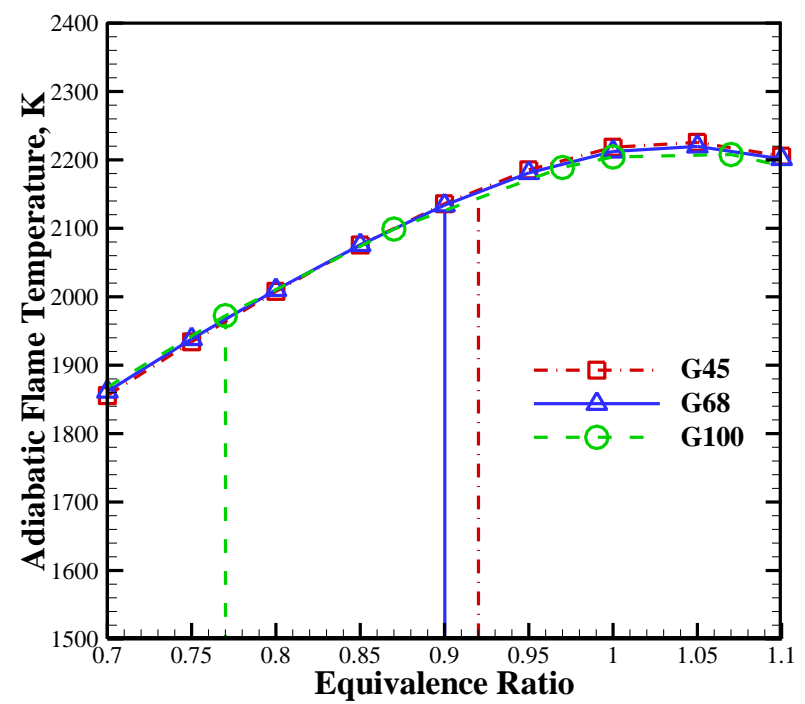

Fig. 3 Adiabatic flame temperatures as the function of equivalence ratio. 


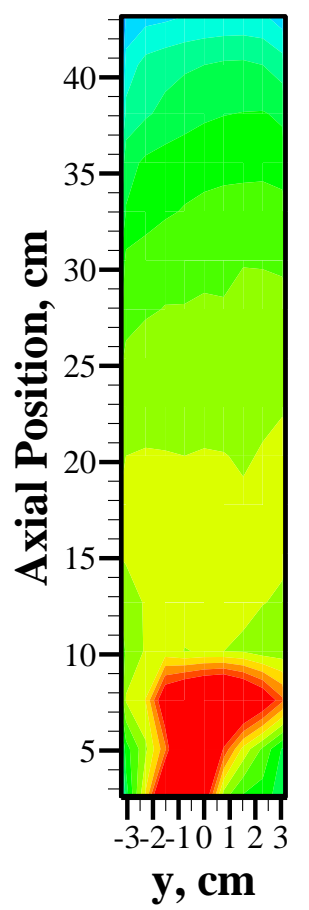

(a)

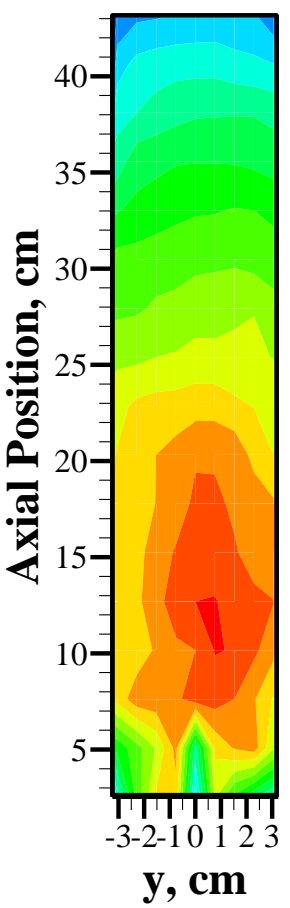

(b)

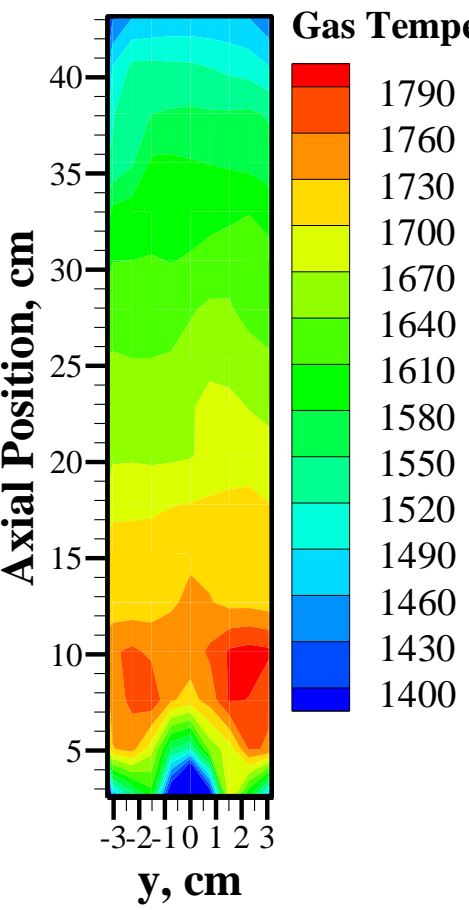

(c)

Fig. 4 Gas temperature contour inside the combustor for (a) G45, and (b) G68 (c) G68A. 

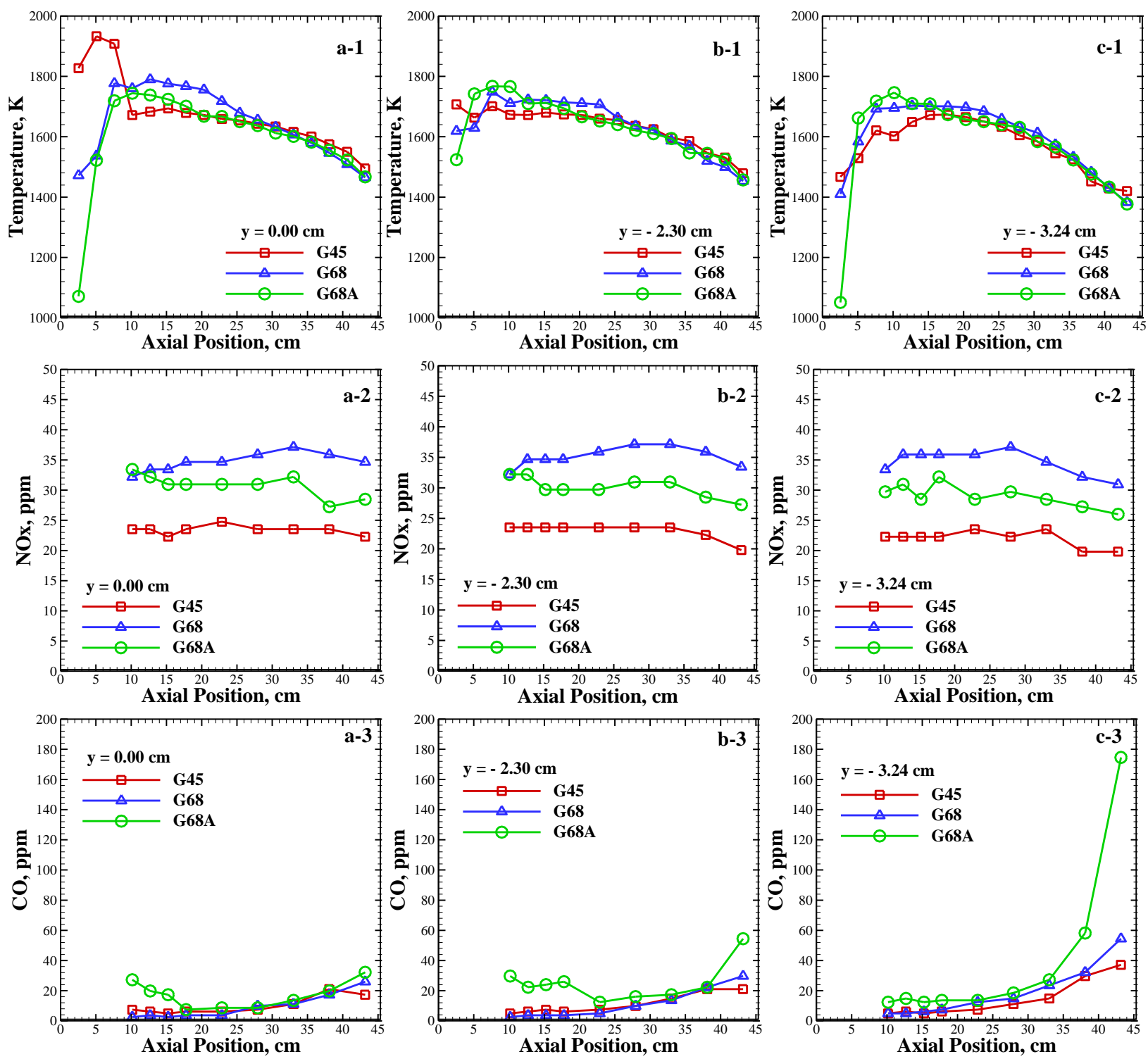

Fig. 5 Axial profiles of gas temperature, $\mathrm{NO}_{\mathrm{X}}$ and $\mathrm{CO}$ concentrations inside the combustor at three radial locations: (a) combustor centerline, (b) between the wall and centerline and (c) close to the wall. 

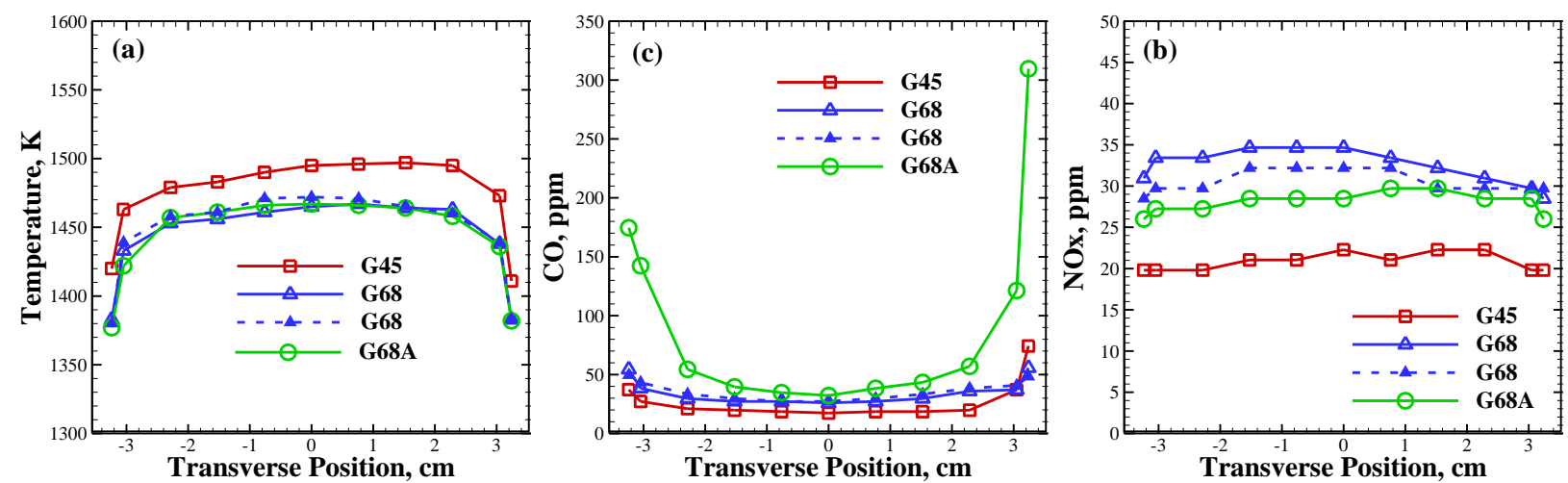

Fig. 6 Transverse profiles of (a) gas temperature (uncorrected), (b) $\mathrm{NO}_{\mathrm{x}}$ emissions and (c) $\mathrm{CO}$ emissions at the combustor exit. 

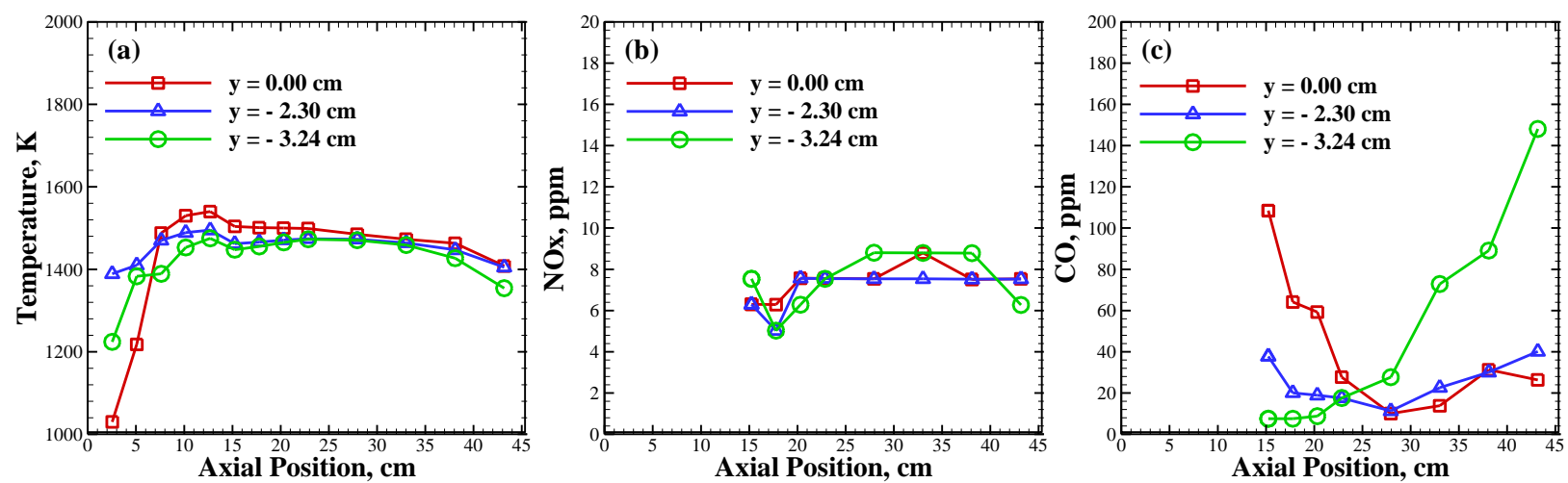

Fig. 7 Axial profiles of (a) gas temperature, (b) $\mathrm{NO}_{\mathrm{x}}$ and (c) $\mathrm{CO}$ emissions inside the combustor for pure glycerol combustion (G100). 